Trinity University

Digital Commons @ Trinity

$9-2015$

\title{
Digital Relics of the Saints of Affliction: HIV/AIDS, Digital Images and the Neoliberalisation of Health Humanitarianism in Contemporary Vietnam
}

Alfred Montoya

Trinity University, amontoya@trinity.edu

Follow this and additional works at: https://digitalcommons.trinity.edu/socanthro_faculty

Part of the Anthropology Commons, and the Sociology Commons

\section{Repository Citation}

Montoya, A. (2015). Digital relics of the saints of affliction: HIV/AIDS, digital images and the neoliberalisation of health humanitarianism in contemporary Vietnam. Mortality, 20(4), 334-350. doi: $10.1080 / 13576275.2015 .1083727$

This Article is brought to you for free and open access by the Sociology and Anthropology Department at Digital Commons @ Trinity. It has been accepted for inclusion in Sociology \& Anthropology Faculty Research by an authorized administrator of Digital Commons @ Trinity. For more information, please contact jcostanz@trinity.edu. 


\title{
Digital relics of the saints of affliction: HIVIAIDS, digital images and the neoliberalisation of health humanitarianism in contemporary Vietnam
}

\author{
ALFRED MONTOYA \\ Department of Sociology E Anthropology, Trinity University, San Antonio, TX, USA
}

\begin{abstract}
Neoliberal logics and calculations have been incorporated into strategies for global health management as rational, technical, scientific guarantors of the integrity and dignity of The Human. NGOs demonstrate, accrue and trade in virtue to gain support, funding and prestige. They field site-visit teams which conduct audits of local partners, review programme data and collect images and narratives of and from the recipients of aid. These images and narratives are used to assess the performance of their local partners and win new donations and volunteers in their home countries. These powerful images and harrowing stories appear in NGO media, establishing the NGOs' humanitarian credentials. Images of the ill, abandoned and poor are put to work among distant actors as assurances that funds are being efficiently applied and that these efforts are 'doing good'. The practice is commonplace within a contemporary neoliberalised health humanitarian apparatus. This process both requires and produces particular subjects and structure relationships between and among NGOs, their posited receiving publics, donors and constituents. Specific imperilled persons and histories are rendered abstractions, immediately graspable and ostensibly unmediated within a specific grammar of global southern suffering. Digitised they become, in a specific, contemporary way, immortal; never changing, but imminently interchangeable
\end{abstract}

KEYwoRDS: HIV/AIDS; neoliberalism; images; humanitarianism; Vietnam

\section{Introduction}

For Dr. Michael C. Kearl (1949-2015).

We pulled off our helmets and blinked in the merciless sunlight, stepping into the narrows of Go Vap District, having come to a stop in a sunbleached courtyard. A middle-aged woman greeted us from the top of an ancient rusted staircase as curious children and half-suspicious neighbours looked on. $\mathrm{Mr} \mathrm{Vu}$, director of an NGO supporting HIV/AIDS infected and affected children for which I was working as a volunteer consultant, directed us up and I stepped aside to allow the French site-visit team to pass. Toting their bags and helmets and expensive digital camera equipment, they gingerly negotiated the groaning narrow stair. Once at the top we crowded into a spare white room, at the centre of which, on a thin mattress, sat the object of our expedition; a rather 
bewildered child of 11 who rubbed his eyes and looked to his aunt for an explanation as to why his afternoon nap had been interrupted by such a strange gaggle of foreigners.

The French team members from AEM unpacked and assembled their cameras. They had asked $\mathrm{Mr} \mathrm{Vu}$ and I to introduce them to the 'sick children', insisting that we come out to this place despite the fact that several HIVpositive children made their home in and had been present at the group's shelter where the site-visit had commenced. $\mathrm{Mr} \mathrm{Vu}$ had obliged, probably still smarting from the chastisement he had received from members of another French NGO (another group funder) months before, after he had refused to gather the group's children a second time after those French visitors failed to appear for a first photo shoot they themselves had insisted upon. Making awkward small-talk with the aunt and the little boy through their hired translator, the French team snapped photo after photo, so many, and in so many directed poses, that it gradually seemed to me, growing uncomfortable at the fringes of the scene, that this collection of images was the real object of our visit.

This article will examine one aspect of what I have elsewhere termed the economy of virtue, the field in which neoliberal logics and calculations (the standard audit, collection and analysis of NGO programme data, demonstrations of 'efficient' application of resources) have been incorporated into strategies for global health management as rational, technical, scientific guarantors of the integrity and dignity of The Human (Montoya, 2012). These neoliberal technologies and logics are a means by which humanitarian organisations demonstrate, accrue and trade in virtue, translating images into symbolic and real capital by deploying them to leverage greater support, funding and prestige. This work is part of a broader push by scholars across disciplines to problematise the neoliberal present. Vincanne Adams has argued that a reliance on an evidence-based medicine that emphasises statistical, experimental and epidemiological models has driven 'a shift in the priorities of caregiving practices in public health such that "people no longer come first"' constituting nothing less than a 'fiscal transformation in how we do global health' (2013b, p. 55). Elsewhere, Adams indicates that relief efforts have been compromised by the application of neoliberal or 'market-driven governance', and the 'transformation of public sector institutions into market-based consortia' (2013a, p. 5). Some of these shifts have 'demanded the incorporation of systematic economic assessment techniques, of which the cost-benefit analysis and the audit are the most salient', conditioning 'a movement toward making interventions cost-effective and scalable' (Biehl \& Petryna, 2013, p. 8).

But virtue, unlike fiscal responsibility or programme coverage, is difficult to demonstrate. How does an NGO assure its volunteers, current and future donors that it is doing good 'out there'? How does an NGO based in Europe or the US make the situations into which they are intervening 'real' to these important contributors? And perhaps more importantly, how does this necessity reflect the new demands of a contemporary health humanitarian apparatus? 
One key technique is the fielding of site-visit teams. Foreign NGOs concerned with HIV/AIDS prevention and control and operating in Vietnam annually send teams to look in on their Vietnamese partners. Team members conduct standard audits of their Vietnamese partner NGOs, review budgets and programme data, tour facilities and the like. They also use the opportunity to collect images and narratives of and from local recipients of aid. These constituents are typically poor, ill, marginalised persons, often women and children, leading difficult lives under demanding conditions at the fringes of a society that has at best been indifferent to, and at worst actively persecuted, them. Ruth McManus argues that the kinds of images we are dealing with 'delineate the parameters of bad death; death that is unacceptable, unconscionable' as the 'purpose and motives that precipitated the extraordinary deaths ... becomes the focus of moral opprobrium' (McManus, 2013, p. 226). Local NGOs, beholden to European, Japanese and US funders, and locked into a precarious and permanent pattern of submitting funding applications, are regularly asked to trot out their constituents (street children, HIV/AIDS infected or affected children, etc.) in acceptable numbers and provide enough transparent documentation to justify previous, and secure future, funding. Writing about HIV/AIDS programmes in Africa, Ann Swidler suggests that 'in the long run, what these organisations really need to provide in order to survive are enough children; so that when the infrequent visitor comes, local relationships can be used to mobilise an acceptable number of children or adults to demonstrate that something is happening on the ground' (Swidler, 2007).

On these visits, the foreign teams take photos and speak to locals. These images and narratives are then used to assess the performance of their local partners. They are also instrumental in winning new donations and volunteers in their home countries. These powerful images and often harrowing stories take centre stage in NGO publications and on NGO websites, tugging on donors' heartstrings and working to establish the NGO's humanitarian credentials. 'NGOs raise substantial amounts of money using these techniques, and where they have tested other images, organisations say that they do not raise as much money' (Plewes \& Stuart, 2007, p. 34). Within a humanitarian economy that prioritises indicators of performance, images of the ill, abandoned and poor are taken and put to work among distant actors as assurances that funds are being adequately and efficiently applied (as in a classical audit) and that these actors are 'doing good' (Fisher, 1997), an accounting of virtue. The images deployed by NGOs transform specific imperilled persons and histories into what I here call, 'saints of affliction'. They are both made to stand in for supposed 'others like them', and share with saints a certain abstraction, an undifferentiated flatness and a measure of unassailability.

These NGOs are responding to the requirements of a new economy where funding, prestige and an NGO's 'market share' depend on the collection, curation and circulation of images and narratives of the afflicted. 'Pictures of desperate, starving people, especially children, have tremendous emotional and psychological impact that more positive pictures do not elicit', write two 
scholars working in this area, and 'agencies that use the more pornographic images are usually larger and have more resources', and have 'thus a deeper impact on public perceptions' (Plewes \& Stuart, 2007, p. 29). In the materials generated and distributed by the NGOs I encountered during my fieldwork in Vietnam, subjects appeared identity-less, deterritorialised, captionless and decontextualised; in the sun in front of a village dwelling, at makeshift desks in poorly appointed classrooms, or on a bedroll in a room crowded with Europeans but shot to look empty. These images attest to what readers and donors might assume to be the close collaboration between the foreign funders and local NGOs serving the local population. In this instance, AEM's 'Vietnam-Cambodia Team' turned out to be a pair of well-meaning NGO representatives who were not based in either Vietnam or Cambodia, who did not speak Khmer or Vietnamese, but rather dropped into the region for quick two-week visits. These images generate a fictional and well-edited relationship between AEM, the team we are meant to infer they are fielding in the region, and the suffering children they depict. They also propose a relationship between these afflicted and vulnerable children, acting as representatives from the state of suffering, and their intended end recipient, the potential donor.

It is by now a commonplace that victim narratives do as much to reify unequal power-relations as respond to them, and that mechanisms that enable the decontextualisation and circulation of images, digital or otherwise, render them impotent as often as they contribute to their power and persuasiveness. My aim is to understand the uses these images are put to and reveal the apparatus that makes them useful and within which they have valence. Drawing from my fieldwork and staying close to the technical aspects of health humanitarianism and human rights discourse, I argue that the use of images like these is now nearly a necessity within a contemporary neoliberalised health humanitarian apparatus.

Portrayals like these are no accidents. The rationale goes like this: the happy pictures do not attract the money. Nor do complex explanations of why people are suffering. And for agencies in the business of aid, it's the dollars that count. (Nathanson, 2013)

Furthermore, these processes both require and produce particular subjects and structure relationships between and among NGOs, their receiving publics, donors and constituents, to such an extent that they in many ways condition what counts as an emergency, and who counts as a proper deserving recipient of attention and aid.

Some might argue that the use of such images is just a well-proven narrative strategy, the common sense means by which NGOs bring to light serious situations around the world. I would counter that this formulation obscures precisely what I have sought to reveal, to look beyond the common-sensical nature of these formations and explore the technical outlines of humanitarianism 
today, to turn a given into a question, a settled formation into a problem to which diverse solutions can then be posed.

This problem has at least two components when we attend to the digital images themselves. Paul Virilio has written about the ways new technologies have historically complicated when, how and if we perceive the real. For Virilio, the eighteenth century closed out the era of 'formal logic' dominated by painting, engraving and etching, architecture, where humans had unmediated access to these representations themselves (Virilio, 1994, p. 63). This was followed by the era of 'dialectic logic', the nineteenth century 'age of photography and film', where images could be reproduced ad infinitum and it was no longer necessary to be in physical proximity to the real object. Finally, for Virilio, we are living through the era of 'paradoxical logic' where 'the real-time image dominates the thing represented, real time subsequently prevailing over real space, virtuality dominating actuality and turning the very concept of reality on its head' (1994, p. 63). Technology, argues Virilio, has effected a sinister transfer in value and perception from the actual to the virtual.

This is apparent in what I am here calling the 'flatness' of the digital image. Unlike Virilio, I argue that the contemporary humanitarian frame makes this 'flattening' of reality a useful, even necessary characteristic. By 'flatness' I mean to index how such images, as they operate within a humanitarian discourse, provide the necessary fiction of an unmediated, contourless, captured completeness. That is to say, on the one hand, the image is, rhetorically speaking, whole, complete, in that it deals the viewer its full effect as an ostensibly unmediated portrait of a reality. Such images, deployed in this way, insist that this suffering, and the work of the NGO dedicated to relieving it, is the truth because we can see it for ourselves. On the other hand, the images, often captioned in the most general way, or captionless altogether, in NGO publications and media, are meant to 'speak for themselves'. However, as French notes in her study of a MOMA exhibition of Khmer Rouge Toul Sleng photographs, images remain frustratingly mute (French, 2002). 'For all its seeming transparency, photography is a highly opaque medium. Because the images are taken directly from life we have the illusion that we can see what is going on in a photograph', but 'they can only speak to what we bring to them, as viewers' (French, 2002). French laments the fact that:

The people in these photographs are individuals, caught up in a particular historical moment. Each has his or her own specific story. But we do not know their stories: we know nothing about them as individuals and, on the basis of this exhibition, almost nothing about the circumstances that brought them here. (2002)

Jean Baudrillard asserts something similar about professional or press images which attest to reality (Baudrillard, 2002). In his terms, the image forces the event to 'emerge to the visible', thus making 'the real substance (of the event) disappear' (Baudrillard, 2002). 'That is why', he writes, 'the more exponential 
the marketing of images is growing the more fantastically grows the indifference towards the real world. Finally, the real world becomes a useless function, a collection of phantom shapes and ghost events' (Baudrillard, 2002). However, one vital aspect of their existence is conserved and conveyed, and it is perhaps the only aspect necessary for the humanitarian frame to function. 'We can only recognise in each person's evident uniqueness a common condition of being human ... They can only convey something more abstract or general. They can speak to what we all share by virtue of our humanity' (French, 2002).

Thus, these types of images are made to speak through their very nature as unspecific. AEM maintains a kind of collage of children from unspecified countries beside its logo on every page of its website. Additionally, each of its country pages features a photo of impoverished children in various circumstances, often enjoying new school materials or resources purchased with organisations funds. Updated country-team photos appear prominently in annual newsletters, bringing potential and current donors information on the programmes AEM is funding. Their Vietnam page highlights their contributions to their major local partner, offering images of children engaged with their shelter educators, sharing meals, or at their studies. It also showcases a photo of a meeting between a French member of AEM's 'Vietnam-Cambodia Team' and the staff of the local NGO, depicting, according to the caption, the 'véritable partenariat' (true partnership) enjoyed by these actors. Similarly, PH, another former group partner, used to adorn each of its website's 'country pages' (Haiti, Madagascar, Senegal, Vietnam) with the same image; a brown-skinned boy and girl, ill-clothed, dishevelled and dirty, standing in the sun. The caption read, simply, 'Enfants'. On its current website, images of children from the four country programmes stream continuously, horizontally, again without caption or comment. Some children appear smiling or horse-playing, some distracted or confused, outside of makeshift dwellings, in funded shelters or before chalkboards in austere classrooms. The ways in which these images are deployed clearly depicts the interchangeability and flatness of these images. We have by now become used to 'reading' these images, not of, in this instance, specific Vietnamese or Senegalese or Haitian persons, but of poor, suffering brown bodies; a contourless representation that works insofar as we understand its grammar. This is a grammar that has been critiqued since the late 1980s as a type of pornography (Nathanson, 2013). It does not matter who these persons are specifically. In fact, as we see, they are quite interchangeable, as long as their images fit within a specific grammar of affliction and intervention. Within the context I have described above, what is at stake in these images becomes not the person, but these symbolic associations generated through the repetition of forms and the affect they produce. Thus, images of the vulnerable or potentially dead, particularly those being served or potentially served by the NGO that is deploying them, generate symbolic capital that can then be leverage or translated into labour and resources. 'These powerful images touch our hearts. They are used by NGOs in the North to raise money for their programmes in the South. And they work', generating $\$ 300$ million in private donations for Canada's five 
largest NGOs in 2004 alone (Plewes \& Stuart, 2007, p. 23). This irony is not lost on local people either. Unite for Sight, an international NGO combatting eye problems, published an interview with Edward, a Malawian collaborator, who said 'NGOs come to the village here to take pictures of people. At church, at the market, on the road, at meetings. Only people who are dressed poorly' (Unite for Sight, 2015). Images of the dying or starving African '(have) become a marketable commodity. They are blown up and displayed at fund-raisers by NGOs, donors and UN agencies; they help organisations to stay in business. The more graphic they are, the more money they help to raise' (Warah, 2011). In an increasingly competitive environment, in which reductions in government support have forced NGOs to rely more heavily on private donations, fundraising has become 'one of the most competitive areas with the NGO community, and there has been little incentive to collaborate on joint experiments' in the use of alternative messaging or imagery (Plewes \& Stuart, 2007, p. 35). This type of messaging, thus, persists. We learn what we are meant to learn within a fixed apparatus and little more: the suffering is there and it requires our immediate attention and intervention through this virtuous organisation.

Humanitarian discourse impels action by figuring crises as threats to an inviolable and universal Humanity, what Redfield calls 'its own categorical rejection of any justification for the sacrifice of human lives' (Redfield, 2005). We must act because we are all part of a common shared Humanity and are all threatened by the possibility of suffering, of violations of our natural human rights. Other scholars have argued that humanitarianism and its discourse operates by extension. By encompassing every last member of the species in an affinity of shared potential victimisation and potential protection, the figure at the centre of this apparatus and discourse, The Human, has built into itself a requirement to act on behalf of distant others in a timely if not immediate way. 'To make a claim on the basis of human rights is to make a claim based on the fact that we are all potential victims and therefore all have an obligation to actively oppose victimisation' (Pendas, 2002). As other scholars have noted, the meta-message behind all human rights claims is some variation of '(You must) do something about this (now)' (Cohen \& Seu, 2002). However, as Hannah Arendt famously argued, 'From the beginning the paradox involved in the declaration of inalienable human rights was that it reckoned with an "abstract" human being who seemed to exist nowhere' (Arendt, 1962). That is, no such conceptual figure previously existed, not in that universal form and not in a form that could command political or juridical weight in a meaningfully consistent way. The digital images we are dealing with now and their deployment within this particular humanitarian system solve this problem by nature of their flatness, that is, by reconfiguring the field of the visible and articulable. Specifically, they enact a generalisability through the tamping down of difference. This universal Humanity (the only thing French admits above can still be conveyed by these types of images) is produced through the flattening of difference, the elimination of distinctions and the obscuring of the uncomfortable relationships of inequality that produce such suffering in the first place, through a shift in perspective. 
This notion of 'flatness' is perhaps better illustrated in two other much-discussed moments that seem to operate in just this way and that have been marked as initiating forms of attention and care with global ambitions. The first is NASA's publication of the famous 'Earthrise' photo, taken on Christmas Eve 1968 by astronauts from the Apollo 8 mission. The photo shows the Earth rising over a lunar horizon. The distant blue planet, small, silent and quite vulnerable-looking against the great black void of space, is often credited with giving rise to the modern environmental movement. 'New imaging technologies enabled humans to perceive their own planet as a whole from outer space for the first time and generated images, some of which were soon to become icons of environmentalism', writes Heise, these images constituting 'allegories of connectedness' which have been critiqued for their 'erasure of political and cultural differences' to suggest 'a unified and balanced world' (Heise, 2008, pp. 20, 24). The Earthrise image appears in Life Magazine's 100 Photographs that Changed the World (Sullivan, 2003). Its entry asserts that the image 'inspired contemplation of our fragile existence', and quotes famed photographer Galen Rowell who calls it 'the most influential environmental photograph ever taken' (Sullivan, 2003, p. 172). The Earthrise image's power is said to be in its depiction of the fragile beauty of the lonely blue marble upon which we are all dependent, so lovely and in jeopardy, floating in a dark cold abyss. We forget that only an extreme shift in perspective, in this instance a spatial one, can produce this sense of commonality, this quite literally globalising effect, a distance great enough to obscure the tremendous geopolitical and socioeconomic inequalities that make it so one nation can devote astronomical sums and resources to send a tiny group of humans into space while a billion lack the most basic necessities. The image tells us we are all the same, equally vulnerable, living on a precarious oasis, but equally that we must go 239,000 miles to gain perspective enough to flatten our stark differences.

It has also been suggested that the humanitarian urgency these images compel comes from just such a place, the consumption of a 'God's-eye view', or the enjoyment derived from indulging in a beefed-up version of 'the gaze' familiar from feminist critical theory, rather than a result of this sense of human commonality. This is a critique found broadly throughout the 'pornography of poverty/suffering' literature.

We must question whether the subjects of the photographs have consented to having their pictures published, and if these messages sell better than more complex and nuanced analyses because they appeal to our emotions, or because they assure us of our own security and superiority,

the success of these images, a reflection of the appeal of schadenfreude, joy from others' sorrow (Oliver, 2006; see also Warah, 2011). Michael Maren unequivocally denounces the use of images of this type as blatant self-congratulation. 'The starving African, exists as a point in space from which we can measure our own wealth, success and prosperity, a darkness against which we can view 
our own cultural triumphs' (Maren, 1997). Only certain representations of Africans, he scathingly writes, appeal to citizens of the global North.

Journalists write about the quiet dignity of the hopelessly dying. If the Africans were merely hungry and poor, begging or conning coins on the streets of Nairobi or Addis Ababa, we might become annoyed and brush them aside. When they steal tape decks from our Land Cruisers, we feel anger and disgust. It is only in their weakness, when their death is inevitable, that we are touched. (Maren, 1997)

Other gender and critical theory scholars have been critical of this scholarship and problematised the use of the concept of 'pornography' within this very literature as a term which is meant to diagnose a putative generalised affective exhaustion while closing down further discussion in a new environment conditioned by new media technologies that have seemingly reshaped 'historical limits on compassion' (Dean, 2003, p. 92). These concerns as a whole have led to the publication of 'codes of conduct' documents by major international NGOs, as well as a new revenue stream in some cases, with organisations offering various 'Cultural Competency Certificate' programmes to combat this problem (see Unite for Sight, 2015). The Red Cross code of conduct explicitly states that 'In our public information we shall portray an objective image of the disaster situation where the capacities and aspirations of disaster victims are highlighted, and not just their vulnerabilities and fears' (International Committee of the Red Cross [ICRC], 1994; see also Child Rights International Network [CRIN], 2009; CONCORD, European NGO Confederation for Relief \& Development, 2006). Though these and other codes governing the use of images of the suffering, dead and dying exist, the use of such images without consent or consideration persists and is ubiquitous, for many of the reasons outlined above.

In Mythologies, Roland Barthes offers a scathing critique of the mid-twentieth century Great Family of Man photographic exhibit whose aim, according to Barthes, was to show 'the universality of human actions in the daily life of all the countries of the world' in short to demonstrate the existence of 'a family of Man', 'a unity of species' that is then 'molarized and sentimentalised' (Barthes, 1980). Barthes' target is this 'ambiguous myth of the human "community," which serves as an alibi to a large part of our humanism'. This myth was constructed, according to Barthes, on the basis of an outward assertion of exotic plurality coupled with an equally powerful claim to an overarching unity that posits a shared 'nature' that precedes ethnic specificity; a purely formal diversity resting on a common human mould. Such declarations rely, for Barthes, on a suppression of History, by which Nature is placed 'at the bottom of History' as its really real basis. That is, at heart is the old trope by which beneath 'the relativity of institutions' and a 'superficial diversity' lies 'the solid rock of a universal human nature'. Barthes considers this a failure of photography. The reproduction of birth or death (or suffering, for our purposes) 'tells 
us, literally, nothing' he writes. 'For these natural facts to gain access to a true language, they must be inserted into a category of knowledge which means postulating that one can transform them, and precisely subject their naturalness to our human criticism'. This is, of course, the very project of humanitarianism; an insertion of these images as elements of a grammar into a category of knowledge that is also a demand for, and a form of, action. For Barthes, the justification for 'all this Adamism' in the last instance 'is to give to the immobility of the world the alibi of a "wisdom" and a "lyricism" which only make the gestures of man look eternal the better to defuse them'. We have, again, an attempt at universalizing humanity through photographic representation that operates through revelation and suppression, through shift in perspective, through narrative-making without History, through a de-specifying flattening.

Second is the tendency of these digital images to reproduce long-standing symbolic visual tropes. Zarzycka and Kleppe identify recurring visual tropes in press photographs and international photography contest submissions, tropes which constitute a set of mobile 'conventions, such as a mourning woman, a young nonwestern girl, or a civilian facing soldiers, that remain solid and unaltered despite their travels across geopolitical contexts' (Zarzycka \& Kleppe, 2013, p. 978). The reoccurrence of such tropes rests on the fact that they are 'easily accessible, undemanding in their familiarity, and well-suited to massmediated collective memory', and are thus particularly effective tools for the coverage of atrocity (Zarzycka \& Kleppe, 2013, p. 979). In their words, such tropes 'replace the un-picturable with the recognisable, transporting internal sensations into a knowable, external world', effectively individualising the social and socialising individuals in a process they call hypertrophy (Zarzycka \& Kleppe, 2013, p. 980). These visual conventions require a small set of elements to be effective. These include the presence of a body (as the site of impending or already accomplished violence), recognisability (intertextual connection to an existing and growing inventory of images familiar to Western visual and literary culture), affective power (compelling outrage, grief, compassion, etc.) and finally symbolic accessibility, such that the figures depicted are made to represent a larger event or issue (Zarzycka \& Kleppe, 2013, p. 981). Holocaust images, for instance, have come to represent all atrocity by extrapolating a 'timeless' meaning from a specific historical event (Zelizer, 1998). Additionally, these images tend to reproduce themselves using the same forms and tropes as their predecessors. Young notes that photography from Cambodia, Bosnia and Rwanda consciously evoked familiar 'concentration camp images' from the early 1940s (Young, 2002). 'The original Holocaust photographs forced the viewer to bear witness: their successors have become a way of labelling a superficial remembering serving a deeper forgetting', writes Zelizer, such that 'Making people witness horrors has subsequently become the acte imaginaire of the twentieth century' (1998). This has a number of pernicious, unintended effects, not least of which is guaranteeing that the context in which atrocities are perceived is that of other atrocities rather than the particular situation depicted (Young, 2002). According to Young, it is in this way that one can 
remember an atrocity and forget the war or situation of inequality that made that atrocity likely, 'atrocity stories' becoming, in the last instance 'only another way of forgetting' (2002). These contemporary images collected and published by NGOs throughout the world take advantage of what has become a common grammar of affliction, the abstraction of suffering based on, but strangely apart from, specific persons and histories. Rather than delegitimising these images, this symbolisation works in tandem with the flatness of decontextualisation to produce an essential element in a humanitarian drama; the apotheosis of victims that conveys a veneer of virtue to the deploying NGO.

According to French, lack of knowledge makes it possible to view these types of images 'as icons of something larger than life rather than evidence of a specific historical atrocity', tragedies having 'moved into the realm of the quasisacred and cannot be treated in public with anything but shock, outrage, and grave respect for the dead' (2002). These recent images, along with the archive of atrocity photos with whom they share a common grammar and in some cases from which they take their staging and form, have been conferred with a timeless meaning, becoming the eternal representation of suffering apart from bodies, persons and specificities. They build a link between the viewer and the victim, indeed creating these positions, by flattening certain differences, but retaining, like Barthes' photographic subjects, an exotic plurality. They generalise to a common Humanity, that is then a call to action. The punctum (Barthes, 1981), that poignant pricking detail that establishes a relationship between the viewer and the image, the working wounding that arrests us, remains death itself. However, the way we read its proximity, and the urgency it provokes, has moved from the background of slow diminishment, or Barthes' afterthought recognition of a past vanishing. Here, death is foregrounded as a quasi-inevitable and immanent certainty. It appears in these images in two forms: as an immediate danger that must be staved off, or as a mounting toll whose tide we must immediately stem. These images operate through our recognition of this form, the foreshortened temporality of emergency compelled by the Human, a figure that conditions all threats to itself as immanent and unable to be ignored.

What is it specifically about the digital image that contributes to this process? And what might this have to do with sainthood?

First, a shift to digital images has radically increased their mobility, circulation and reach. 'The culture of electronic media', writes McManus, 'is characterised by full aural, and oral sensory experiences, and global real-time coverage gives events immediacy and salience despite geographic dislocation' (2013, p. 211). McManus attributes increase in the number of depictions of deaths and the diminishment of taboos associated with representing death and suffering to recent technological transformations (2013, p. 210). She contends that the 'presence of actual ordinary deaths has ... emerged from the shadows', becoming the focus of celebrity biopics, artistic exhibitions, documentaries and as part of the reality television industry (McManus, 2013, p. 215). McManus indicates that the ubiquity of information-communications technologies has 
provided an opportunity not only for ordinary deaths to take their place among other types of death whose public representation had been long accepted, but has provided an avenue by which representation of 'the most morally sensitive domain of death representation', that of 'real extraordinary deaths' (from catastrophes, bombings, assassinations, atrocities, executions and the like) has become possible (2013, p. 221; see also Campbell, 2004). For McManus, 'more heterogeneous and ambiguous representations' of 'real death' is possible, and these are 'more available, more graphic, more varied and more emotionalized' (2013, p. 225). This is certainly also true of the availability, variability and emotionality of representations of survivors (or potential victims) of violence and deprivations of all kinds.

Digital images are also absolutely portable, extremely manipulable, infinitely reproducible, and all the while, extraordinarily durable. Digital technology ensures that images of these afflicted persons are virtually immortal, as they are able to proliferate at an extraordinary rate and are collected in a distributed network. Digital images also provide the same promise of transparency as conventional photographs. '(T)here was a certainty that such a thing had existed; not a question of exactitude, but of reality ... the fact was established without method' (Barthes, 1981). However, by their nature, digital images offer a new level of immediacy. These images can be taken anywhere in the world and uploaded or emailed instantaneously, rapidly reaching their intended audiences faster, with lower cost and fewer barriers than their physical counterparts. Consequently, these images are perceived as even less mediated than their film counterparts, readily available, their content instantly graspable. The foreshortened temporality of digital images and the ubiquity of digital image-making equipment ramps up the perceived quality and in some ways, even the believability of the old 'man-on-the-spot' account. Images captured on cell phone cameras which end up on the nightly news feel more accidental, less staged or deliberate or distant than their analogue counterparts. For his part, Baudrillard calls the digitisation of images the 'last violence' done to and by the image (2002). 'The real has not even time to take place as it is immediately produced as virtual reality' (Baudrillard, emphasis mine, 2002).

No direct capture of the picture anymore, no presence of a real object in an irrevocable moment and face-to-face, which constitutes the magic of photography and of the image generally as acting, as singular event - last glimmer of reality in a world devoted to hyperreality ... While the photo testifies of an absence of something that really took place, but according to Barthes now went away forever, today the photo, the genuine analog photograph, would rather testify of a presence, of an immediate presence of the subject to the object - what does not happen anymore in the computerizing of images. (Baudrillard, 2002)

Finally, their unproblematic storage and their wide circulation on the Web, coupled with their linkage to a timeless representation of suffering, sacrifice and virtue, forms the basis of a weird, provisional type of immortality for their 
subjects (see also Kearl, 2010). There is, of course, no decay of the digital, only problems of access, publicity, deletion. This means that our bewildered HIVpositive orphan, or rather his image and the meanings piled upon it, can go on working for the NGO in various capacities long after he himself is gone. In fact, within a certain logic, it hardly matters at all if he survived or not. As other scholars of death have rightly argued, the dead (or nearly dead) can be deployed for political, social and symbolic uses, their uses often mediated and extended by new technologies (Kearl \& Rinaldi, 1983).

\section{Conclusion}

Jacques Derrida's concept of 'globalatinization' describes the proliferation and extension of religious forms and discourses as a result of globalisation in a framework that underpins seemingly secular institutions, including technoscience and capitalism themselves (Derrida, 2002). Digital images deployed by NGOs render specific imperilled persons and histories into 'saints'. They share with saints a certain abstraction, an undifferentiated flatness and a measure of unassailability. Fassin and Rechtman write about the ways demonstrating trauma 'becomes an additional way of testifying to the realities of persecution' countering suspicion and the assailability of claims to asylum, such that the politics of reparation, testimony and truth are bound up a dialectical relationship with suspicion and cynicism (Fassin \& Rechtman, 2009, p. 10). It becomes impossible to argue against these images; they 'speak for themselves'. The persons in the images, their existence and meaning, are not at stake; only reception and response are at stake. These images testify that these persons are there, afflicted, standing in for an idea and the unseen thousands more 'like them', linked to us by the tenuous formulation (ever in need of reinscription) of our 'universal Humanity'. As icons (Perlmutter, 1998) or symbols, they are 'flat', immediately graspable, ostensibly unmediated. Digitised they become, in a specific, contemporary way, immortal; never changing, but imminently interchangeable.

The digital images collected by AEM or $\mathrm{PH}$ are truly relics of these contemporary saints of affliction, relics referring to 'that which remains or is left behind, esp. after destruction or wasting away ... the remnant, residue of a nation or people' or 'objects vested with interest' (Oxford English Dictionary [OED], 2011). These are 'indexical icons', operating 'according to a conventional semantic rule of likeness, and by being existentially linked (to the person) as well' (Tambiah, 1985, p. 156). Like religious relics, these images not only venerate those special ones from whom they were taken, but more importantly, sanctify and confer special favour upon their bearers. These images and narratives solidify the merit and virtue of the NGO that has collected, curated and communicated them, a virtue that increases in proportion to the shocking qualities of the image, the severity of the issue ostensibly being addressed by 
the group. This virtue, as I have elsewhere contended, can then be leveraged and exchanged for symbolic and real capital.

Some might argue that the complex relationship this arrangement posits between the subjects of these images and potential donors is such that it renders all donations a self-serving act. Baudrillard claims that uses of these images of misery constitute novel forms of violence.

This realistic image, however, does not catch at all what really is, but what should not be - death and misery - what should not exist, from our moral and humanistic point of view. And at the same time making an aesthetic and commercial, perfectly immoral use and abuse of this misery. (2002)

Some quality work has been done on public reception and interpretation of human rights appeals (see Cohen \& Seu, 2002). My analysis is distinct. My fieldwork stayed close to the day-to-day operations of two Vietnamese NGOs, their dealings with their international funders, and subsequently, in a less intense way, with the operations of these distant funders. Images and narratives circulating through these arrangements obviously have many related, but distinct uses, though they conform to what I have elsewhere identified as the general form of a neoliberalised humanitarianism; one that relies on various forms of audit, efficiency instruments, and other indicators of performance to secure the integrity and dignity of The Human (Montoya, 2012). I wanted to understand, and I hope to have communicated here, some of the constraints these actors worked under, the form of the humanitarian apparatus within which these actors operated, how this requires the policing of certain norms and engagement with certain knowledge-making practices. As Michael Fischer has noted, 'Assertions of universal human rights and rights of humanitarian intervention can be double-sided, subordinating as well as emancipating' (Fischer, 2009, p. 259). I hope to have demonstrated this here. These small European and Vietnamese NGOs, constrained by resource and other limitations, found their actions conditioned by a humanitarian apparatus that prioritises fiscal performance, that is increasingly measuring all value in dollar-to-unit-benefit calculations, and organising itself around a figure, The Human, that renders all threats to itself as acute emergencies.

Over the course of several months that included the site-visit described at the outset of this article, and others, I had the opportunity to meet the young boy described above numerous times. Most often, I would receive a harried call from $\mathrm{Mr} \mathrm{Vu}$, saying that the boy was once again at Paediatric Hospital Number Two, suffering from respiratory or other ailments. We would visit with him and his aunt, the boy perched upon a painted iron bed, joking and chatting through a wheezing cough, the late afternoon sun filtered through the slats in the French shutters, while outside the washed linens flapped in the breeze on lines in the hard-packed dirt courtyards.

Under these conditions, an 11-year-old Vietnamese orphan, HIV positive from birth, lover of chicken wings and dubbed Chinese fantasy dramas, 
frequent hospital patient, witty teaser of nurses, was rendered an icon, his image a shorthand for others 'like himself', the poor, the abandoned, the ill. A palimpsest scrubbed clean of the specific details of his life, but conspicuously anchored to a familiar imaginary of global southern suffering, the boy was made useful, fashioned into a cypher, one that could be immediately apprehended, placed into a relationship with distant foreign actors, produce affect and urgency through a narrative form we have grown so familiar with that it no longer requires explanation or justification.

Today, humanitarian virtue finds its expression and its proof in account books, digital photographs and the circulation of narratives that link aid workers and donors to suffering bodies, that attest to good will and credibility, in a literally spectacular performance. In the time of virtue, NGOs working in good faith, within the largely unconsidered constraints of a contemporary humanitarian apparatus, engage with a discourse and technical processes that turn chronic problems into acute emergencies, individual human beings into icons of affliction, and digital images into relics, the signs of passing of modern saints upon whom are projected today's fears of suffering and tomorrow's hopes for salvation.

\section{Disclosure statement}

No potential conflict of interest was reported by the author.

\section{REFERENCES}

Adams, V. (2013a). Markets of Sorrow, Labors of Faith: New Orleans in the Wake of Katrina. Durham: Duke University Press.

Adams, V. (2013b). Evidence based global public health: Subjects, profits, erasures. In J. BiEHL \& A. Petryna (Eds.), When people come first: Critical studies in global health (pp. 54-90). Princeton, NJ: Princeton University Press.

ARENDT, H. (1962). The origins of totalitarianism. Cleveland, OH: Meridian Books.

Barthes, R. (1980). The great family of man. In Mythologies (A. LaVERs, Trans., pp. 100-102). New York, NY: Hill and Wan.

Barthes, R. (1981). Camera Lucida: Reflections on photography. New York, NY: Hill and Wang.

Baudrillard, J. (2002). The violence of the image. Paper presented at the International Symposium attached to "media_city", Seoul Biennial.

Biehl, J., \& Petryna, A. (Eds.). (2013). When people come first: Critical studies in global health. Princeton, NJ: Princeton University Press.

Campbell, D. (2004, January). Horrific blindness: Images of death in contemporary media. Fournal for Cultural Research, 8, 55-74.

Child Rights International Network. (2009). The use of images of children in the media. Retrieved March 28, 2015, from https://www.crin.org/en/library/publications/use-images-chil dren-media.

Cohen, S., \& SeU, B. (2002). Knowing enough not to feel too much: Emotional thinking about human rights appeals. In M. Bradley \& P. Petro (Eds.), Truth claims: Representation and human rights (pp. 187-201). New Brunswick, NJ: Rutgers University Press. 
CONCORD, European NGO Confederation for Relief and Development. (2006). Code of conduct on images and messages. Retrieved March 28, 2015, from http://www.concordeurope. $\mathrm{org} /$ publications/item/115-code-of-conduct-on-images-and-messages?highlight=YTo2OntpOj A7czo0OiJjb2RIIjtpOjE7czoyOiJvZiI7aToyO3M6NzoiY29uZHVjdCI7aTozO3M6NzoiY29k ZSBvZiI7aTo0O3M6MTU6ImNvZGUgb2YgY29uZHVjdCI7aTo1O3M6MTA6Im9mIGN vbmR1Y3QiO30=

Dean, C. (2003). Empathy, pornography, and suffering. Differences: A Fournal of Feminist Cultural Studies, 14, 88-124.

DerRIDA, J. (2002). Acts of religion. London: Routledge.

Fassin, D., \& Rechtman, R. (2009). The empire of trauma: An inquiry into the condition of victimhood. Princeton, NJ: Princeton University Press.

Fischer, M. (2009). Anthropological futures. Durham: Duke University Press.

FISHER, W. (1997). Doing good? The politics and anti-politics of NGO practices. Annual Review of Anthropology, 26, 439-464.

French, L. (2002). Exhibiting terror. In M. Bradley \& P. Petro (Eds.), Truth claims: Representation and human rights (pp. 131-155). New Brunswick, NJ: Rutgers University Press.

HeIse, U. (2008). Sense of place and sense of planet: The environmental imagination of the global. Oxford: Oxford University Press.

INTERnational CommitTeE OF THE RED CROss. (1994). The code of conduct for the international red cross and red crescent movement and nongovernmental organisations (NGOs) in disaster relief. Retrieved March 28, 2015, from https://www.icrc.org/eng/assets/files/publications/icrc-0021067.pdf

Kearl, M. (2010, February). The proliferation of postselves in American civic and popular cultures. Mortality, 15, 47-63.

Kearl, M., \& Rinaldi, A. (1983, March). The political uses of the dead as symbols in contemporary civil religions. Social Forces, 61, 693-708.

MAREN, M. (1997). The road to hell: The ravaging effects of foreign aid and international charity. New York, NY: The Free Press.

McManus, R. (2013). Death in a global age. New York, NY: Palgrave MacMillan.

Montoya, A. (2012). From 'The People' to 'The Human': HIV/AIDS, neoliberalism and the economy of virtue in contemporary Vietnam. Positions: East Asia Cultures Critique, 20, 561-591.

Nathanson, J. (2013). The pornography of poverty: Reframing the discourse of international aid's representations of starving children. Canadian fournal of Communication, 38, 103-120.

Oliver, A. (2006). The 'Pornography of Poverty' and the 'Brothel Without Walls': Understanding the impact of art on development. Undercurrent, 3, 18-25.

Oxford English Dictionary. (2011). Relic. Online version. Retrieved August 10, 2011, from http://www.oed.com/view/Entry/161910?rskey=EB8KMc\&result=1\&isAdvanced=false\#eid

Pendas, D. (2002). 'Law not Vengeance': Human rights, the rule of law, and the claims of memory in german holocaust trials. In M. BRAdley \& P. PeTro (Eds.), Truth claims: Representation and Human rights (pp. 23-41). New Brunswick, NJ: Rutgers University Press.

Perlmutter, D. (1998). Photojournalism and foreign policy: Icons of outrage in international crises. Westport, CT: Praeger.

Plewes, B., \& STUART, R. (2007). The pornography of poverty: A cautionary fundraising tale. In D. BeLl \& CoICAUD (Eds.), Ethics in action: The ethical challenges of international human rights nongovernmental organizations (pp. p23-37). New York, NY: Cambridge University Press.

Redfield, P. (2005). Doctors, borders and life in crisis. Cultural Anthropology, 20, 328-361.

Sullivan, R. (Ed.). (2003). Life: 100 photographs that changed the world. New York, NY: Time.

SwIDLER, A. (2007). Syncretism and subversion in AIDS governance: How locals cope with global demands. In K. Nana Poku, A. Whiteside \& B. Sandkjaer (Eds.), AIDS and governance (pp. 145-163). Burlington, VT: Ashgate Publishing Company.

Тамвіан, S. (1985). Culture, thought and social action. Cambridge, MA: Harvard University Press.

UNITE FOR SIGHT. (2015). Ethics and photography in developing countries. Retrieved April 15, 2015, from http://www.uniteforsight.org/global-health-university/photography-ethics

VIRILIO, P. (1994). The vision machine. Bloomington, IN: University of Indiana Press.

Warah, R. (2011). Enough of these 'Dying African' images. In R. WARAH (Ed.), Red soil and roasted maize: Selected essays and articles on contemporary Kenya (pp. 141-144). Bloomington, IN: Author House Press. 
Young, M. (2002). Remembering to forget. In M. Bradley \& P. Petro (Eds.), Truth claims: Representation and human rights (pp. 11-21). New Brunswick, NJ: Rutgers University Press.

ZARZYCKA, M., \& KLEPPE, M. (2013). Awards, archives, and affects: Tropes in the world press photo contest, 2009-2011. Media, Culture \& Society, 35, 977-995.

ZELIZER, B. (1998). Remembering to forget: Holocaust memory through the camera's eye. Chicago, IL: University of Chicago Press.

\section{Biographical Notes}

Dr Alfred Montoya is an assistant professor of Anthropology in the Department of Sociology \& Anthropology at Trinity University, San Antonio, TX, USA. His work is on modes of governance around HIV/AIDS prevention and control in Vietnam, and on global health humanitarianism. 